\title{
Assembly of a Cyclic Dimer Silver(I) Complex Encapsulating Two $\mathrm{BF}_{4}^{-}$lons
}

\author{
Joobeom Sco, Seok-Tac Moon, Jineun Kim, Shim Sung Lee, and Ki-Min Park ${ }^{\star}$ \\ Departmen of Chemistry and Research Instinte of Nantal Sciences, \\ Gyeongsang National University, Chinin 660-701, Korea \\ Received June 20, 2003
}

Key Words : $\mathrm{N}_{2} \mathrm{~S}$ donor ligand, $\mathrm{X}$-ray structure, Cyclic dimer complex, $\mathrm{BF}_{4}^{-}$ion

It is a challenging work to capture ionic species or small molecules as guests. Thus, the construction of self-assembled cyclic oligomer complexes composed of metal centres connected by acyclic organic ligands ${ }^{1,2}$ has been a subject of great interest together with the inclusion phenomena of macrocyclic ligands" in the supramolecular chemistry. The majority of the organic-inorgaic hybrid macrocyclic structures reported so far have been based on bis-monodentate ligands such as 4.4'-bipyridine and its derivatives interconnected by rigid or flexible spacers. ${ }^{2}$ The same type of ligands has been also used for the formation of coordination network. ${ }^{+}$

We are currently engaged in the construction of the coordination polymers by using series of dipicolyl sulfides including 1, bis(3-pyridylmethyl)sulfide, which is a potentially tridentate ligand to act as a flexible building blocks. In the reaction of 1 with $\mathrm{AgBF}_{4}$, in contrast to other reactions we have employed, neither the I-D nor 2-D coordination polymers have been isolated, but rather discrete cyclic dimer complex was obtained. A remarkable feature of this cyclic structure is the encapsulation of two $\mathrm{BF}_{4}{ }^{-}$anions in its 20 membered cavity. Although the rational control of molecular frameworks by anions have become a recent interest in crystal engineering. ${ }^{5}$ little is known about anion-encapsulated $\mathrm{M}_{2} \mathrm{~L}_{2}$ [M: metal. L: ligand] complexes.' 'lo our best knowledge, few examples of two $\mathrm{BF}_{4}^{-}$-encapsulated $\mathrm{M}_{2} \mathrm{~L}_{2}$ complexes have been reported so far. ${ }^{\text {Ic }}$ We present here the synthesis and structural details of this complex, which was<smiles>c1cncc(CSCc2cccnc2)c1</smiles>

characterized by X-ray diffraction and ESI-Mass.

Reaction of 1 with $\mathrm{AgBF}_{4}$ in the molar ratio $\mathrm{l}: \mathrm{l}$ in methanol gave off-white precipitates immediately, which were identified as the discrete complex $[\mathrm{Ag}(1)]_{2} \cdot 2 \mathrm{BH}+$ by the single crystal $\mathrm{X}$-ray analysis. Elemental analysis of the complex is consistent with a 1 : I ligand:metal ratio. The IR spectrum shows an intense $\mathrm{BF}_{4}^{-}$band at $1053 \mathrm{~cm}^{-1}$. The ESI mass spectrum in DMF shows peaks at $m / z 323,325$,

\footnotetext{
"Corresponding author. Fax: 182-55-753-7614; E-mail: kmpark (ùnongae.gsnu.ac.kr
}

539, 541, 732 and 734 corresponding to $\left[{ }^{107} \mathrm{Ag}(\mathbf{1})\right]^{-}$, $\left[{ }^{109} \mathrm{Ag}(\mathbf{1})\right]^{+},\left[{ }^{107} \mathrm{Ag}(\mathbf{1})_{2}\right]^{+},\left[{ }^{109} \mathrm{Ag}(\mathbf{1})_{2}\right]^{-},\left\{\left[{ }^{107} \mathrm{Ag}(\mathbf{1})\right]_{2}(\mathrm{BF}+)\right\}^{-}$, and $\left\{\left[{ }^{100} \mathrm{Ag}(1)\right]_{2}\left(\mathrm{BF}_{4}\right)\right\}^{+}$. The crystals with high quality for $X$-ray analysis were obtained by the vapor diffusion of diethyl ether into the DMSO solution of the precipitates. Crystal parameters and procedural information corresponding to data collection and structure refinements are given in Table I. The geometric parameters of the complex are shown in lable 2.

According to X-ray crystal structure analysis (Figure 1), the discrete cyclodimeric complex, $[\mathrm{Ag}(\mathbf{1})]_{2}-2 \mathrm{BF}$, was constructed. A striking feature is that two $\mathrm{BF}_{4}^{-}$anions are positioned in the cavity. In the cationic $[\mathrm{Ag}(1)]_{2}{ }^{2+}$, each $\mathrm{Ag}$ atom is coordinated linearly by two pyridine $\mathrm{N}$ atoms from two different ligands (1) [N-Ag-N 166.4(2) $]$ while each ligand binds two $\mathrm{Ag}$ atoms in cis,cis-mode, leading to the

Table 1. Crystal $]_{\circ g}$ raphic Data for $[A g(1)]_{2} \cdot 2 B F_{\downarrow}$

\begin{tabular}{|c|c|}
\hline Pommala & $\mathrm{C}_{2,1} \mathrm{I}_{21} \wedge \mathrm{g}_{2} \mathrm{H}_{2} \mathrm{I}_{\mathrm{S}} \mathrm{N}_{1} \mathrm{~S}_{2}$ \\
\hline lw. & 821,95 \\
\hline space group & $(2 \%$ \\
\hline$a . A$ & $13.627(1)$ \\
\hline$b . \wedge$ & $14.009(2)$ \\
\hline $\cos$ & $15.609(2)$ \\
\hline$\beta^{\circ}$ & $106.977(2)$ \\
\hline$\therefore \AA^{3}$ & $2580.1(5)$ \\
\hline$\%$ & 4 \\
\hline$D_{\mathrm{r}, \mathrm{d}} \mathrm{g} \mathrm{ecm}^{-3}$ & 1.916 \\
\hline$\mu \cdot \mathrm{mm}^{-1}$ & 1.597 \\
\hline$R\lfloor/>2 \sigma(I)\rfloor$ & $\begin{array}{l}R_{1}=0.0596 \\
w R_{2}=0.1478\end{array}$ \\
\hline
\end{tabular}

Table 2. Selected Geometric Parameters $\left(X .^{\circ}\right)$ for $|\Lambda g(l)|_{2} 2\left[\left.3\right|_{+}\right.$

\begin{tabular}{llll}
\hline $\mathrm{Ag}(1)-\mathrm{N}(1)$ & $2.152(5)$ & $\mathrm{Ag}(1)-\mathrm{N}(2)^{\mathrm{i}}$ & $2.141(5)$ \\
$\mathrm{N}(1)-\mathrm{Ag}(1)-\mathrm{N}(2)^{\mathrm{i}}$ & $166.5(2)$ & & \\
$\mathrm{Ag}(1) \cdots \mathrm{Ag}(1)^{i}$ & $7.212(2)$ & $\mathrm{Ag}(1) \cdots \mathrm{F}(3)$ & $3.31(4)$ \\
$\mathrm{Ag}(1) \cdots \mathrm{N}(4)$ & $3.56(1)$ & $\mathrm{Ag}(1)^{\mathrm{i}} \cdots \mathrm{F}(2)$ & $3.468(6)$ \\
$\mathrm{Ag}(1) \cdots \mathrm{S}(1)^{\mathrm{i}}$ & $3.106(2)$ & & \\
C(2)-C(6)-S(1)-C(7) & $89.1(6)$ & $\mathrm{C}(6)-\mathrm{S}(1)-\mathrm{C}(7)-\mathrm{C}(8)$ & $73.0(5)$ \\
Dihedral angle betwecn two pyridine rings & $1.79(5)$ \\
\hline
\end{tabular}

Symmetry transformations used to generate equivalent atoms: i) $-x-$ $1 / 2,-y \cdot 1 / 2,-z+1:$ ij $)-x+1 / 2,2$ । $1 / 2,(-z+1 / 2) । 1$ 


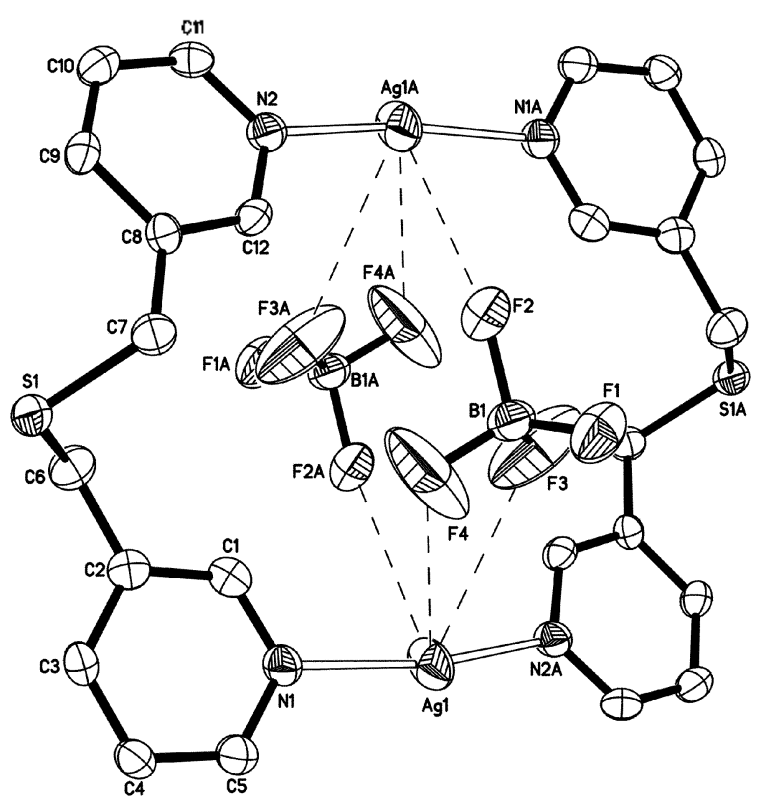

Figure I. Structure of complex $[A g(I)]_{2} \cdot 2|3|^{*}+$ with atomic labeling scheme. Hydrogen atoms are omitted for clarity:

formation of a 20-membered macrocyclic motif. Two pyridine rings coordinated to the $\mathrm{Ag}$ atom are tilted by $13.7(1)^{\circ}$ with respect to each other. The Ag-N distances [Ag(1)-N(1) 2.152(5) $\AA, A g(1)-N(2 A) 2.141(5) \AA]$ are shorter than those found in the silver(J)-bis(2-pyridylmethyl)sulfide complex. "The asymmetric unit contains one $\mathrm{Ag}$ atom, one ligand, and one $\mathrm{BF}_{4}{ }_{4}^{-}$anion by a crystallographic inversion center at the midpoint between the two $\mathrm{Ag}$ atoms. Each non-coordinating $\mathrm{S}$ atom oriented exo-fashion, and thus the pseudo-rectangular framework of the molecule is folded into the stair-shape. The dimension of the pseudo-rectangle is defined by the distances between the centroids of pyridyl rings $(6.6 \times 7.0 \AA)$ and intramolecular $\mathrm{Ag} \cdots \mathrm{Ag}$ separation $[7.212(2) \AA]$. This is in contrast to the two-fold symmetric dimer of bis(2pyridylmethyl)sulfide, an isomer of $\mathbf{1}$, in which threecoordinate $\mathrm{Ag}$ atoms are bound in $\mathrm{N}-\mathrm{Ag}-\mathrm{N}$ fashion together with the each $S$ donor to form a cyclic dimer with a much smaller empty cavity." Each $\mathrm{BF}_{4}^{-}$ion is located slightly above and below the folded rectangular plane and with the distance $\mathrm{Ag}(1) \cdots \mathrm{F}(3)$ of $3.31(6) \AA$, which indicates a long range interaction.

According to the packing structure (Figure 2), the deviation from the linearity of N-Ag-N angle is due to the weak intermolecular Ag $\cdots$ S interaction (3.106(2) Å). Furthermore, the cyclic dimmers pack in layers, allowing offset $\pi-\pi$ stacking ${ }^{7}$ with the separation between the centroids of 3.69 $\AA$. The dihedral angle between the pyridyl ring planes is $1.79(5)^{\circ}$

In conclusion, unusual twenty-membered cyclic dimer encapsulating two $\mathrm{BF}_{4}{ }^{-}$anions was obtained by the selfassembly of the tridentate $\mathrm{N}_{2} \mathrm{~S}$ donor ligand (1) and silver ion. We are currently investigating the subtle factors influencing the formation of discrete or continuous complexes using dipicolyl sulfide derivatives including $\mathbf{1}$.

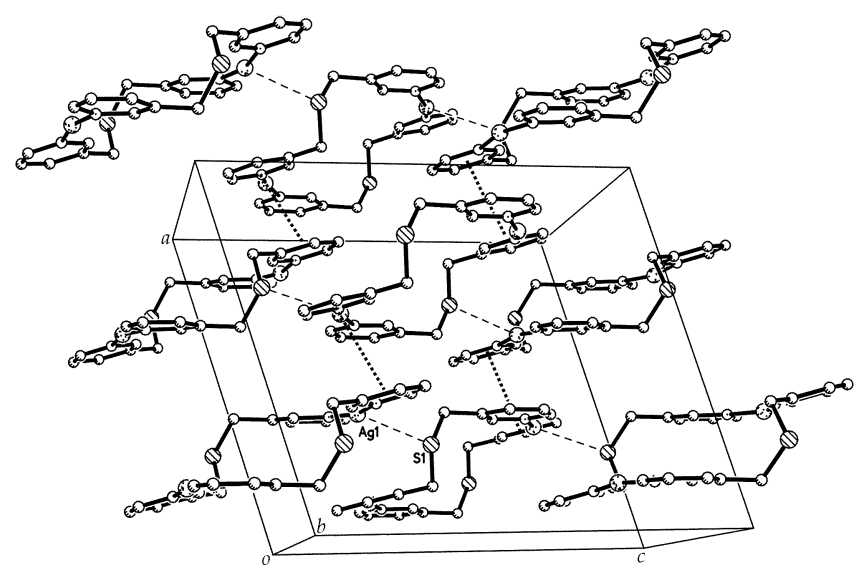

Figure 2. Projection showing lle stait-shaped cyclic dimers with

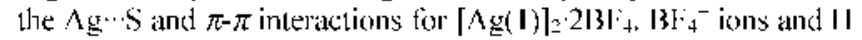
atoms arc omitted for clarity.

\section{Experimental Section}

Synthesis. The ligand 1, bis(3-pyridylmethyl)sulfide, was conveniently synthesized by the reaction of $\mathrm{Na}_{2} \mathrm{~S}$ and 3picolyl chloride hydrochloride, and the detailed procedure will be described in elsewhere. Reaction of 1 (50.0 mg. $0.231 \mathrm{mmol}$ ) with $\mathrm{AgBr}, 4(50.0 \mathrm{mg}, 0.257 \mathrm{mmol})$ in methanol gave off-white precipitate immediately. Analytical data for $\left\{[\mathrm{Ag}(1)]\left(\mathrm{BF}_{1}\right)\right\}_{2}: \mathrm{Mp} .209-213^{\circ} \mathrm{C}$ (dec.). Anal. Calc. for $\mathrm{C}_{21} \mathrm{H}_{2,4} \mathrm{Ag}_{2} \mathrm{~B}_{2} \mathrm{~F}_{8} \mathrm{~N}_{1} \mathrm{~S}_{2}: \mathrm{C}, 35.07 ; \mathrm{H}, 2.94 ; \mathrm{N}, 6.82 ; \mathrm{S}, 7.80$. Found: $\mathrm{C}, 34.97 ; \mathrm{H}, 3.05 ; \mathrm{N}, 6.43 ; \mathrm{S}, 8.23 \%$. IR $(\mathrm{KBr}$, $\mathrm{cm}^{-1}$ ): $3448(\mathrm{br}), 1582,1474,1423,1053$ (s, br, BF, $\left.{ }^{-}\right), 813$, 711. ESI-MS: $m=323\left[{ }^{107} \mathrm{Ag}(1)\right]^{+}, 325\left[{ }^{1069} \mathrm{Ag}(1)\right]^{+}, 539$ $\left[{ }^{107} \mathrm{Ag}(1)_{2}\right]^{-}, 541\left[{ }^{1096} \mathrm{Ag}(1)_{2}\right]^{-}, 732\left\{\left[^{107} \mathrm{Ag}(1)\right]_{2}\left(\mathrm{BF}_{4}\right)\right\}^{+}, 734$ $\left\{\left[^{109} \mathrm{Ag}(1)\right]_{2}(\mathrm{Br}, 1)\right\}^{-}$.

Crystallographic Structure Determination. All data were collected on a Bruker Smart diffractometer equipped with a graphite monochromated Mo K $\alpha(\lambda=0.71073 \AA)$ radiation source and a $\mathrm{CCD}$ detector at ambient temperature. The 45 frames of two dimensional diffraction images were collected and processed to obtain the cell parameters and orientation matrix. The first 50 frames were retaken after complete data collection. The crystal showed no significant decay and no correction was applied for absorption or decay. The frame data were processed to give structure factors using the program SAINT. ${ }^{8}$ The structure was solved by direct methods and refined by full matrix least squares methods on $F^{2}$ for all data using SHELXTL software. 'The non-hydrogen atoms were refined anisotropically, and hydrogen atoms were placed in calculated positions and refined with a riding model with $U_{\text {iso }}$ constrained to be 1.2 times $U_{\mathrm{vy}}$ of the parent atom.

Crystallographic data for the structure reported in this paper have been deposited with the Cambridge Crystallographic Data Center [CCDC deposit number 205088]. Copies of the data can be obtained free of charge via hitp:/ www: codecam.actuk/perlicatreq/catreq.cgi (or from the CCDC, 12 Union Road, Cambridge CB2 JEZ, UK; fax: (+44) I223336-033; e-mail: deposit(ầccdc.cam.ac.uk). 
Acknowledgement. This work was supported by Korea Research Foundation Grant (KRF-2001-005-D00006). Xray crystallography and ESI mass spectrum were performed on Bruker SMART CCD and Quattro II at the Centeral Laboratory (Gyeongsang National University) and the Korea Basic Science Institute Daegu Branch. respectively.

\section{References}

1. (a) Hirsch. K. A.: Wilson. S. R.: Moore. J. S. J. Am. Chem. Soc. 1997. 119. 10401. (b) Liu. J.: Liu. H.-K.: Feng. X.-L.: Zhang. H.X: Zhou. Z.-Y.: Chan. A. S. C.: Kang. B.-S. horg. Chent. Commin. 2001 f, 674. (c) Crabtree. S. P: Batsanot. A. S: Howard I. A. K: Kilner. M. Polyedron 1998. 17,367.

2. (a) Fujita. M. Acc. Chem. Res. 1999, 32. 53. (b) Leininger S: Olenyuk. B.: Stang. P. J. Chem. Rev, 2000. 100. 853. (c) Hartshorn. C. M.: Steel. P. J. J. Chem. Soc.. Dallon Trans. 1998. 3935. (d) Hartshorn. C. M.: Steel. P. J. J. Chem. Soc. Dallon Trants. 1998, 3927. (e) Jung, O.-K.: Lee. Y.-A.: Kim. Y. I.: Hong. I. Cnstal Growth \& Design $\mathbf{2 0 0 2} 2.497$.

3. Lindoy. L. F. The Chemisty of Afacrocydic Ligand Complexes; Cambridge University Press: Cambridge. U. K.. 1989
4. (a) Moulton. B.: Zaworotko, M. J. Chem. Rev 2001. 101, 1629 (b) Robson. R. J. Chem. Soc. Dalton Trans. 2000. 3735. (c) Biradha. K.: Hongo. Y: Fujita. M. Angew: Chem., Im. Ed. 2000. 39. 3843. (d) Kim. Y. T.: Yoo. K. H.: Park. K.-M.: Hong. T.: Tung. O.-S. Bull. Korean Chent Soc. 2002, 23. 1744. (e) Jung. O.-K. Kim, Y. J.; Lee. Y.-A.; Yoo, K. H: Chae. H. K. Bull. Komam Chem. Soc, $2001,22.534$.

5. (a) Jung. O.-S.: Kiml. Y. T.: Lee. Y.-A.: Park. K.-M:: Lee. S. S. Inorg. Chent 2003. 42. 844. (b) Jung. O.-S.: Kim. Y. J.: Lee. Y.A.: Park. J. K.: Chae. H. K. J. Am. Chem, Soc. 2000.122. 9921. (c) Beer, P. D.; Gale. P. A. Angew. Chem., hnt. Ed. 2001. to. 486. (d) Min, K. S.; Suh, M. P. J. Am. Chem. Soc. 2000. 122. 6834

6. Caradoc-Davies. P. L.: Hanton. L. R.: Lee. K. Chem. Commun 2000. 783 .

7. (a) Shetty. A. S.: Zhang. J.: Moore. T. S. J. Ant. Chem. Soc. 1996. 118. 1019. (b) Desiraju. G. R. Crnstal Engineering: The Design of Organic Solids: Elsevier: New York, U. S. A.. 1989: Chapter 4.

8. Bruker. SMART and SANT: Awa Detector Control and Integration Software Ier: 5.0. Bruker Analytical X-ray Instruments: Madison. Wisconsin. 1998.

9. Bruker. SHELXTL: Stmicture Determination Programs lér. 5.16: Bruker Analytical X-ray Instruments: Madison. Wisconsin, 1998. 